Tri Siwi Agustina

\title{
Storytelling Sebagai Strategi Bisnis Sosial Start-Up Ojek Syar'i Berbasis Aplikasi di Surabaya
}

\author{
Tri Siwi Agustina \\ Universitas Airlangga \\ Agustina2772@gmail.com
}

\begin{abstract}
Abstrak
Syarihub adalah startup bisnis sosial yang digagas 2 orang pemuda di kota Surabaya yang bergerak pada transportasi layanan publik berbasis aplikasi. Sadar menantang pendahulunya yakni Gojek, Grab dan Uber, Syarihub memilih untuk melayani hanya perempuan dan anak - anak. Menghadapi sengitnya persaingan usaha pada bisnis transportasi layanan publik berbasis aplikasi dan dakwah menuntut pengelola Syarihub jeli merumuskan strategi. Sebagai bisnis sosial, storytelling dinilai sebagai cara terbaik untuk berbagi dan menyampaikan nilai - nilai sosial (social value). Cerita dapat mewakili pengalaman, bercerita dapat mengoordinasikan masa lalu dan harapan di masa depan. Penelitian ini bertujuan untuk mengetahui apakah storytelling merupakan media promosi yang tepat bagi Syarihub sebagai sebuah bisnis sosial serta mengetahui strategi storytelling yang telah dilakukan oleh Syarihub dalam menghadapi tantangan - tantangan dalam mengepakkan sayap bisnisnya. Pendekatan yang digunakan dalam penelitian ini adalah kualitatif deskriptif dengan sumber data primer (wawancara dengan pendiri sekaligus pengelola Syarihub) dan data sekunder yakni studi literatur dari berbagai postingan yang dibuat oleh Syarihub pada website, media sosial maupun liputan media yang dipublikasikan sejak tahun 2015 hingga 2019. Hasil penelitian menunjukkan bahwa storytelling meupakan media yang tepat untuk bisnis sosial dan strategi storytelling yang ditempuh Syarihub adalah dalam bentuk Data driven storytelling, Philanthropy storytelling, Customer-led storytelling dan Immersial story telling dan telah memenuhi kaidah efektifas storytelling yaitu TRUTH (Topical, Relevant, Unusual, Trouble, Human).
\end{abstract}

Kata Kunci: Bisnis Sosial, Start Up, Storytelling, transportasi layanan publik berbasis aplikasi

\section{Pendahuluan}

Social Enterprise atau bisnis sosial saat ini merupakan topik yang menarik untuk didiskusikan pada berbagai pertemuan bisnis maupun pertemuan ilmiah karena keunikan model bisnis social enterprise dan dampaknya pada masyarakat, bertambahnya jumlah sosiopreneur serta beragamnya jenis bisnis sosial di Indonesia. Model bisnis social enterprise menggabungkan proses bisnis yang menghasilkan profit dengan diiringi oleh kesadaran untuk berkontribusi dalam menyelesaikan masalah - masalah sosial (Ryder dan Vogeley, 2017). Salah satu contoh start-up yang menggunakan bentuk model bisnis dari social enterprise adalah Syarihub. Syarihub adalah startup bisnis sosial yang digagas 2 orang pemuda di kota Surabaya yang bergerak pada transportasi layanan publik berbasis aplikasi. Sadar menantang pendahulunya yakni Gojek, Grab dan Uber, Syarihub memilih untuk fokus pada niche market yakni perempuan dan anak - anak (khusus anak laki - laki yang disyaratkan adalah belum akil baligh). 
Model bisnis sosial yang ditawarkan oleh Syarihub adalah berusaha mengatasi ketimpangan yang dialami kaum wanita akan akses ke pekerjaan yang layak dan penghasilan yang lebih rendah dibandingkan pria. Oleh karena itu Syarihub membuka seluas-luasnya kesempatan kerja bagi perempuan sebagai pengendara ojek. Selain itu, misi sosial lain Syarihub adalah menekan angka kriminalitas dan juga kekerasan seksual terhadap perempuan dan anak - anak sebagai pengguna transportasi publik di Indonesia.

Saat diluncurkan pada tahun 2015, wilayah operasional Syarihub adalah Surabaya dan sekitarnya, seiring berjalannya waktu saat ini wilayah operasional Syarihub telah tersebar di berbagai kota, yakni Sidoarjo , Malang dan Makasar. Dalam kurun waktu 4 tahun, satu persatu tantangan untuk mengepakkan sayap usahanya sebagai social enterprise mulai berdatangan, misalnya tantangan dalam meyakinkan masyarakat akan model bisnis Syarihub, tumbuhnya pesaing - pesaing baru hingga langkah re-branding.

Dinamika tantangan yang ditemui Syarihub menuntut kejelian untuk meghadapinya. Berbagai strategi dilakukan oleh pengelola Syarihub contohnya apabila para pesaingnya masih berfokus pada layanan antar penumpang, barang dan kuliner, Syarihub mengembangkan layanannya tidak hanya mengantar penumpang barang dan kuliner saja namun juga melakukan antar jemput anak sekolah, mengasuh anak hingga jasa Catering Subuh.

Penelitian sebelumnya dalam konteks bisnis sosial di Indonesia pernah dilakukan oleh Lindawati pada tahun 2018 dengan judul "Kekuatan Cerita Pada Bisnis Sosial" yang menyimpulkan bahwa sebagai bisnis sosial, menurut Lindawati (2018) salah satu strategi untuk dapat meraih konsumen dan juga mengembangkan jejaring (networking) adalah melalui storytelling, dengan kekuatan jejaring, maka dampak sosial yang ingin dicapai oleh bisnis tersebut akan lebih terasa dan meluas. Lebih lanjut diungkapkan bahwa perkembangan media digital melahirkan lingkungan yang menguntungkan para sosiopreneur setidaknya dengan dua cara. Pertama, media digital mengubah cara orang berbisnis. Bagi bisnis konvensional mendatangkan efisiensi, sedangkan bagi bisnis sosial yang bukan profit oriented, media digital membuat logika bisnis sosial menjadi kelaziman yang mudah diterima. Kedua, kehadiran media digital mendorong berkembangnya storytelling marketing. Jika bisnis komersial harus menggali ceritanya, bisnis sosial selalu hadir membawa cerita. Sebab, tanpa cerita, social entrepreneurship akan tampak seperti bisnis pada umumnya.

Terkait dengan uraian tersebut diatas, maka penelitian ini rumusan masalah pada penelitian ini adalah "Apakah storytelling merupakan media promosi yang tepat bagi Syarihub sebagai sebuah bisnis sosial serta apakah strategi storytelling yang telah dilakukan oleh Syarihub dalam menghadapi tantangan - tantangan dalam mengembangkan bisnis sosialnya".

\section{Landasan Teori}

Mair dan Marti (2004) dan Seelos dan Marti (2005) berpendapat bahwa kewirausahaan sosial adalah aktivitas yang menggunakan pendekatan entrepreneur dalam menciptakan model bisnis baru untuk membantu orang - orang miskin sehingga mengurangi permasalahan sosial dan menciptakan trasformasi sosial. Karakteristik ini yang membuat kewirausahaan sosial berbeda dengan aktivitas entrepreneurship lainnya dimana prioritas utama sosial entrepreneurship terletak pada upaya mempromosikan nilai - nilai sosial dan pembangunan.

Wan-Tzu, \& Shyhnan (2016) berpendapat bahwa meningkatnya bisnis sosial (social enterprise) menuntut sociopreneur untuk mencari cara - cara yang inovatif untuk dua hal yakni : pertama, mengubah cara pandang masyarakat tentang bisnis sosial Cara pandang masyarakat terhadap bisnis sosial yang kurang tepat yakni -false welfare dan true enrichment with high ethical standards. False Welfare atau kesejahteraan yang palsu yang dimaksud adalah anggapan bahwa tidak perlu menggunakan istilah "sosial", karena pada dasarnya semua 
aktivitas entrepreneurship adalah memberi manfaat bagi orang banyak. Sedangkan true enrichment with high ethical standards atau pencapaian kekayaan dengan menggunakan standar-standar etika yang tinggi, kurang lebih adalah menggunakan isu - isu sosial agar masyarakat membeli produk bisnisnya dengan alasan kemanusiaan . Cara pandang yang salah tersebut mendatangkan tantangan bagi sosiopreneur untuk meyakinkan masyarakat bahwa mengelola entitas kewirausahaan bisnis sosial berbeda dengan cara mengelola kewirausahaan bisnis pada umumnya.

Kedua, strategi promosi yang digunakan bisnis sosial yang unik karena menantang strategi promosi pemasaran yang konvensional. Pesatnya teknologi, informasi dan komunikasi di era Revolusi Industri 4.0 juga mendorong berkembangnya storytelling marketing. Lindawati (2018) menambahkan bahwa cerita digunakan sebagai content marketing karena adanya kejenuhan masyarakat akan pesan persuasif komersial dan tumbuhnya kesadaran masyarakat akan etika bisnis (good business). Wan-Tzu, \& Shyhnan (2016) menambahkan bahwa cerita (story) mampu menyentuh hati dan emosi seseorang, serta melalui cerita dapat menggerakan seseorang untuk melakukan suatu action atau tindakan. Storytelling dalam bisnis sosial merupakan cara yang baik untuk berbagi dan menyampaikan nilai untuk masalah sosial. Cerita dapat mewakili pengalaman, bercerita dapat mengoordinasikan masa lalu dan harapan di masa depan. Bisnis sosial dapat memanfaatkan storytelling untuk menciptakan nilai (value) dan memberikan kesan pada audiens untuk melihat, merasakannya, dan kemudian mengingatnya.

Manfaat storytelling lainnya bagi bisnis sosial diungkapkan oleh Roundy (2014) yang menyatakan bahwa seorang sociopreneur sudah seharusnya membangun narasi untuk berkomunikasi dengan stakeholder. Narasi atau cerita ini mempunyai peran besar dalam membangun relasi, baik dengan konsumen, relawan, maupun investor , artinya selain menarik minat konsumen cerita bagi sosiopreneur juga penting untuk membangun multistakeholder partnership (Lindawati, 2018).

Selanjutnya Lindawati (2018) menjelaskan bentuk - bentuk strategi storytelling. Pertama, Data Driven Storytelling. Strategi ini menggunakan data sebagai konten cerita. Melalui penyajian data yang kompleks, tentu dengan bahasa yang sederhana, diharapkan dapat membangkitkan kesadaran atas sebuah permasalahan. Strategi kedua, Phylantropic storytelling sebagai pemenuhan tuntutan konsumen akan transparansi dan ingin mengetahui lebih dalam mengenai perusahaan. Bagaimana mereka menjalankan bisnis, memperlakukan pekerja, etika kerjanya, dan bagaimana mereka mendapatkan bahan bakunya. Hal ini berkaitan dengan meningkatnya kesadaran global mengenai good bussines. Strategi ketiga adalah Customer-led storytelling, dimana data menunjukkan bahwa $92 \%$ orang lebih mempercayai peer dibandingkan dengan iklan konvensional. Sehingga, menghadirkan cerita sukses dari para user akan meningkatkan engagement masyarakat terhadap bisnis sosial tersebut. Sebagai tambahan terdapat strategi : Immersial Story Telling atau Visual Story Telling yaitu : strategi pemasaran yang memanfaatkan narasi menarik, menempatkan konsumen di jantung cerita dan direalisasikan dengan media visual yang secara emosional untuk pengalaman berbelanja kostumer. Strategi yang lainnya adalah Dark Marketing dan juga Media Ad. Ketiga strategi terakhir tidak terungkap pada penelitian tersebut karena peneliti sebelumnya tidak mendapatkan contoh implementasi.

James Lush, direktur Lush Digital Media, mengatakan, terdapat lima elemen yang bisa membuat storytelling dalam pemasaran lebih efektif yaitu Topical, Relevant, Unusual, Trouble dan Human (TRUTH). Topical artinya mengetahui informasi seperti apa yang dibutuhkan audiensi saat ini. Relevant artinya , membuat storytelling yang relevan dengan target yang lebih spesifik. Unusual artinya mencari sudut pandang berbeda agar ada kejutan dalam cerita , Trouble artinya menampilkan konflik untuk membuat cerita tetap menarik. dan Human artinya 
menampilkan manusia dalam cerita hingga audiensi merasakan kedekatan emosi dengan tokohnya.

\section{Metode Penelitian}

Pendekatan yang digunakan dalam penelitian ini adalah kualitatif deskriptif, dengan alasan pendekatan ini dapat memberikan ruang bagi seorang peneliti untuk menjadi alat dalam memahami realitas empirik dengan lebih mendalam serta memberikan peluang untuk mengembangkan model penelitian sesuai dengan kondisi empirik yang dihadapi. Sedangkan metode deskriptif dipilih berdasar tujuan penelitian ini yang menekankan pada eksplorasi variabel. Teknik pengumpulan data yang digunakan adalah bersumber dari data primer yakni melakukan wawancara dengan pendiri (founder) Syarihub yaitu Evilita Andriani dan Reza Zamir, serta juga menggunakan data sekunder yakni studi literatur dari berbagai postingan yang dibuat oleh Syarihub pada website, media sosial maupun liputan media yang dipublikasikan sejak tahun 2015 hingga 2019.

\section{Pembahasan}

Sejak diluncurkan pada bulan Maret tahun 2015 dengan nama PT. Ojek Syari Surabaya (Ojesy) lalu berganti nama pada bulan Agustus 2015 menjadi PT. Ojek Syari Indonesia (Ojesy) dan transformasi nama terakhir adalah pada awal tahun 2019 beralih menjadi "Syarihub", terdapat berbagai tantangan yang ditemui untuk mengepakan sayap usahanya sebagai social enterprise, mulai dari meyakinkan masyarakat akan model bisnis Syarihub, tumbuhnya pesaing - pesaing baru hingga konflik internal.

Di era kemajuan teknologi saat ini, semua hal bisa diakses secara online, termasuk jika konsumen ingin membeli suatu produk. Para pemilik usaha berlomba-lomba untuk ikut serta mempromosikan produknya secara online lewat media sosial, website maupun aplikasi. Demikian pula dengan Syarihub yang memanfaatkan website dan media sosial dalam aktivitas pemasaran mereka.

Pada bagian tentang pembahasan akan diulas bagaimana strategi strorytelling Syarihub pada berbagai media online yang digunakan dalam menghadapi tantangan yang telah disebutkan dibagian sebelumnya yakni meyakinkan masyarakat akan model bisnis Syarihub, tmengantisipasi umbuhnya pesaing - pesaing baru hingga storytelling untuk keperluan ReBranding Syarihub.

\section{Storytelling untuk meyakinkan masyarakat}

Ide awal pendiri Syarihub adalah pertama didasarkan pada fenomena yang terjadi bahwa transportasi publik di Indonesia belum menjamin keamanan dan kenyamanan penumpangnya terutama perempuan dan anak - anak. Maraknya terjadi kasus kriminalitas yang memakan korban kaum perempuan dan anak - anak seperti kejahatan seksual, kasus kasus kriminalitas dan penculikan. Kedua Indonesia adalah negara dengan penduduk muslim terbesar di dunia dimana jumlah penduduk perempuan lebih banyak daripada laki - laki. Didalam nilai - nilai agama Islam, seorang perempuan tidak diperbolehkan bepergian selain dengan muhrimnya. Nilai - nilai tersebut tentunya membatasi ruang gerak dan mobilitas wanita dalam kegiatan sehari - hari. Padahal, wanita memiliki kegiatan yang lebih banyak dibanding pria, dimulai dari berbelanja ke pasar di pagi hari, mengantar dan menjemput anak ke sekolah, hingga membeli keperluan rumah tangga (Agustina, 2019). Hal tersebut didukung pula oleh 
fenomena lain bahwa adanya ketimpangan yang dialami kaum wanita untuk mendapatkan akses ke pekerjaan yang layak dan penghasilan yang lebih rendah dibandingkan pria.

Tentunya tidak mudah untuk mempersuasi masyarakat tentang layanan social enterprise seperti yang disampaikan oleh Wan-Tzu, \& Shyhnan (2016) berpendapat bahwa meningkatnya bisnis sosial (social enterprise) menuntut sociopreneur untuk mencari cara cara yang inovatif untuk membawa perubahan cara pandang pada masyarakat tentang keberadaan bisnis sosial. Upaya meyakinkan masyarakat teruji saat Syarihub beroperasional pada bulan - bulan awal di tahun 2015. Masyarakat kota Surabaya saat itu sedang dibuai layanan ojek online seperti Gojek, Uber dan Grab yang menawarkan harga murah. Tarif 1 kilometer awal yang ditawarkan Ojesy sebesar Rp8 ribu dan kilometer selanjutnya Rp3 ribu Sementara Gojek menetapkan tarif promo untuk perjalanan 1 sampai 10 kilometer perusahaan menetapkan tarif Rp 12.000, sementara itu, untuk jarak 10 hingga 15 kilometer dikenakan tarif Rp 15.000 (Sumber https://gojekinfoupdate.blogspot.com, 2019) dan yang lebih ekstrim, Grabride Grab menerapkan tarif promo Rp 5.000, lebih murah dibandingkan Gojek (Sumber : www.cnnindonesia.com ,2015). Manajemen Ojesy mengakui bahwa tarifnya jauh lebih mahal dari ojek online lainnya. Alasannya karena armadanya masih terbatas. Selain itu yang paling krusial adalah mencari pengemudi wanita tidak semudah mencari pengemudi pria. Perbedaan tariff tersebut tentunya membawa tantangan tersendiri bagi manajemen Syarihub ditengah euforia masyarakat Surabaya yang sedang menikmati "menu baru layanan transportasi publik". Mengapa demikian ? karena ojek konvensional belum lazim beroperasi di kota Surabaya tidak seperti ojek konvensional yang sudah lama menjadi alternatif layanan transportasi bagi masyarakat Jakarta atau wilayah Jawa Barat.

Menjawab hal tersebut strategi yang dilakukan oleh Syarihub adalah : Data Driven Storytelling. Strategi ini menggunakan data sebagai konten cerita. Melalui penyajian data tentang tingginya angka kekerasan terhadap perempuan diharapkan dapat membangkitkan kesadaran atas sebuah permasalahan seperti terdeskripsikan pada postingan Instagram Syarihub (Gambar 1 - kiri).

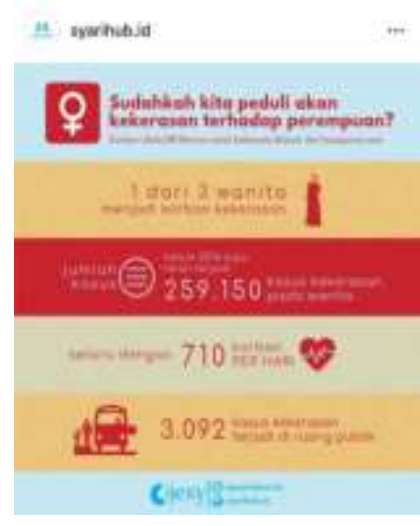

Sumber Instagram (2018)
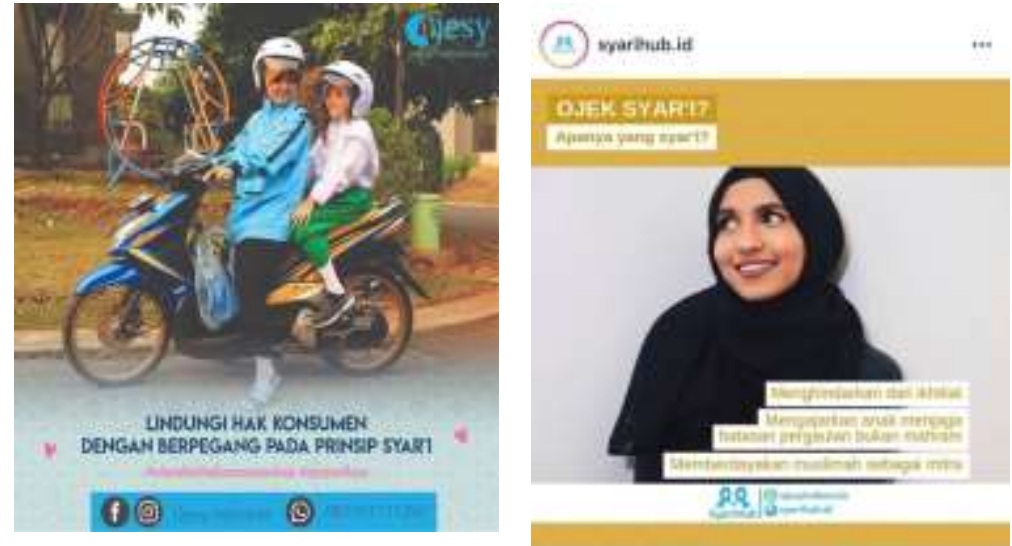

Sumber : akun Instagram Syarihub (2018)

\section{Gambar 1 Data driven storytelling pada instagram}


Untuk mempersuasi kaum wanita sebagai calon penumpang (user) bahwa tarif Syarihub merupakan tarif yang wajar sekalipun dibandingkan dengan pesaingnya, karena Syarihub memenuhi hak - hak mereka sebagai wanita dalam menggunakan layanan ojek online yang tidak terpenuhi pada ojek online lainnya seperti nampak pada Gambar 1 tengah dapat dilihat bahwa mitra pengendara adalah wanita, mengenakan jilbab dan tidak berpakaian ketat disertai dengan penjelasan "Lindungi Hak Konsumen Dengan Berpegang pada Prinsip Syari". Storytelling pada postingan tersebut memenuhi kaidah topical artinya memberikan informasi tentang layanan apa yang dibutuhkan konsumen saat ini (menggunakan layanan transportasi umum dengan driver wanita) serta relevant karena storytelling yang dibuat cocok dengan target yang lebih spesifik yakni (wanita dan anak - anak). Pada Gambar 1 sebelah kanan storytelling berupa postingan disertai gambar bersifat topical karena menjelaskan tentang nilai - nilai syar'i dalam layanan Syarihub, yaitu dapat menghindarkan dari ihtilat atau bersentuhan/bersandaran antara laki-laki dan perempuan, saat berkendara, Bagi anak-anak, dapat mengajarkan untuk menjaga batas pergaulan dengan temannya yang bukan mahram dan yang ketiga meningkatkan kualitas hidup muslimah yang menjadi mitra (sahabat pengendara).

Strategi kedua adalah Phylantropic storytelling sebagai upaya untuk memenuhi tuntutan konsumen akan transparansi dan ingin mengetahui lebih dalam mengenai Syarihub termasuk juga bagaimana mereka menjalankan bisnis, memperlakukan pekerja, etika kerjanya, dan bagaimana mereka mendapatkan bahan bakunya, berikut adalah contoh - contoh Phylantropic storytelling yang telah dilakukan oleh Syarihub :

Untuk bisa diterima sebagai Sahabat Pengendara, terdapat sejumlah syarat yang harus dipenuhi yakni harus bisa berkendara motor dengan baik, memiliki motor dengan kondisi dan kelengkapan surat yang aman, wanita berjilbab dan berpakaian tidak ketat, berusia maksimal 45 tahun dan dapat mengoperasikan smartphone. Selain itu juga masih ada beberapa syarat lagi yaitu siap menerima order ojek di daerah sesuai wilayah tinggal atau lokasi yang dikehendaki, memiliki waktu longgar minimal lima jam per hari untuk menerima orderan, dan yang paling penting adalah surat izin bekerja dari mahromnya, maka phylantropic storytelling yang pernah dilakukan olehSyarihub dalam bentuk postingan di Instagram adalah sebagai berikut :
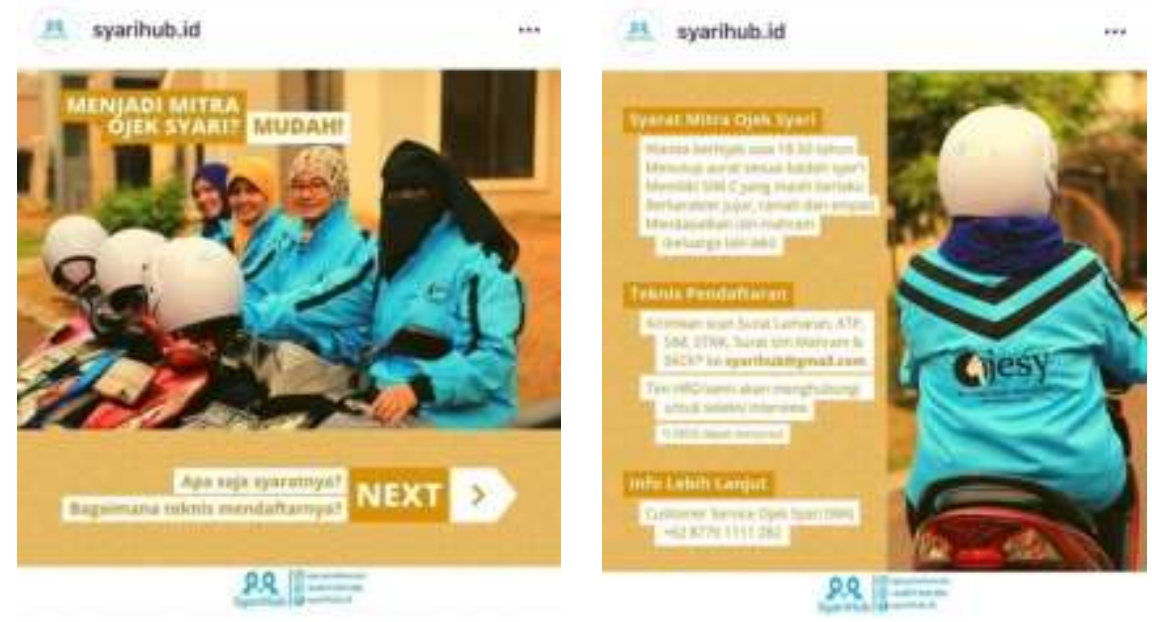

Sumber : akun Instagram Syarihub.id (2018) Sumber : akun Instagram Syarihub.id (2018) 
Demikian pula sebagai bentuk etika bisnis perusahaan pada karyawan terutama terkait dengan keselamatan para pegawai , Syarihub memiliki peraturan yang tidak mengijinkan Sahabat Pengendara ngetem dijalan serta ditetapkannya pembatasan waktu bekerja. Seperti disampaikan oleh Reza Zamir mewakili manajemen Ojesy menyampaikan alasan yang mendasari peraturan tersebut pada selular.id :

"Manajemen Ojesy sadar bahwa kami harus menjaga kehormatan para wanita yang menjadi Sahabat Pengendara. Bergabungnya para wanita untuk menjadi Sahabat Pengendara adalah atas dorongan ingin membantu dan memberikan rasa aman dan nyaman buat para wanita atas layanan ojek yang dibutuhkan para wanita yang tidak mempunyai mahram untuk bepergian, untuk para wanita yang membutuhkan kenyamanan saat berada di belakang orang yang memboncengnya. Dan ini dilakukan atas dasar mempertimbangkan manfaat yang bisa didapatkan untuk banyak pihak tanpa menafikan ada sisi mudharat yang bisa saja timbul atas kondisi-kondisi yang tak terduga ketika di jalan," - reza Zamir (sumber : https://selular.id/2015/10/ojek-syari-larangdriver-mangkal-di-jalan)

“...kita sangat menjaga kesehatan dan keselamatan sahabat pengendara, jam kerjanya hanya dibatasi hingga jam 7 malam". - Evilita Andriani (sumber : https://youtu.be/alld44x9Fbc )

Storytelling pada liputan media tentang Syarihub menunjukkan storytelling Syarihub dalam menjamin keselamatan dan kesehatan sahabat pengendara sebagai bentuk pertanggung jawaban terhadap karyawan serta menjamin keselamatan user-nya.

Contoh lain tentang phylantropic storytelling dari Syarihub adalah berupa testimoni pengendara Syarihub Dikutip dari akun facebook Ojesy Semarang, manfaat sosial yang dirasakan oleh sahabat pengendara dari Semarang)
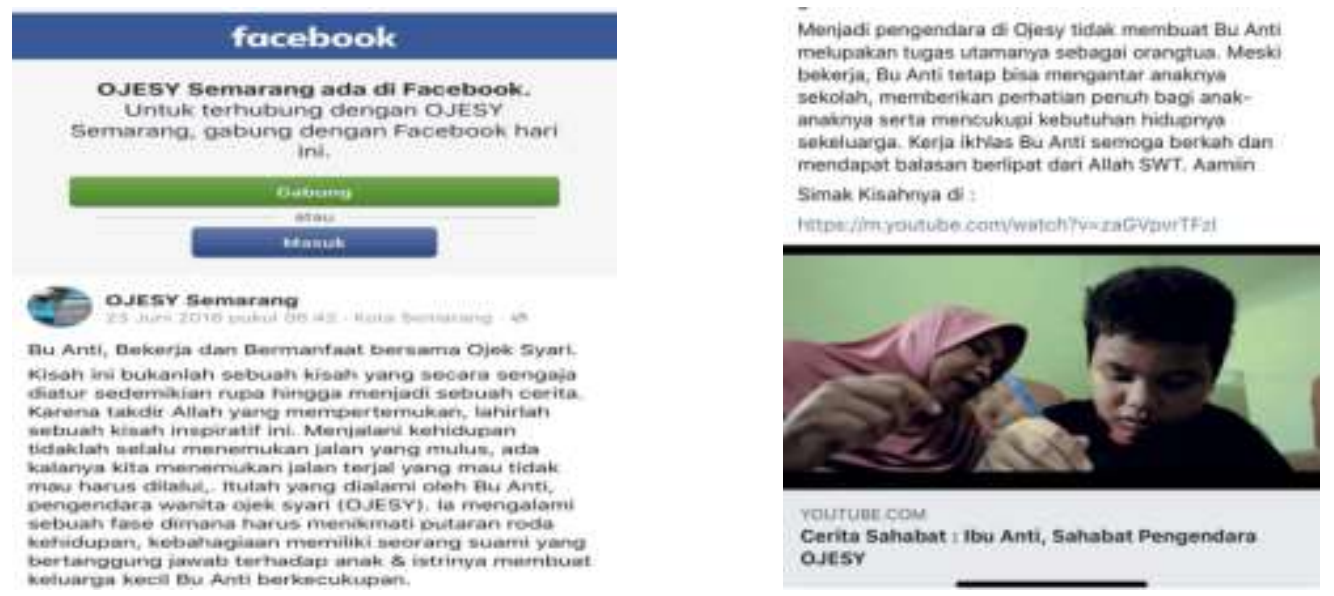

Gambar 3 : Phylantropic storytelling Syarihub pada Facebook

Sumber : Akun Facebook OJESY Semarang, 23 Juni 2016 


\section{Tri Siwi Agustina}

Storytelling di facebook tersebut menampilkan sesuatu yang un-usual karena menceritakan pengalaman dari sudut pandang yang berbeda yaitu sahabat pengendara setelah bergabung dengan Syarihub serta menampilkan sisi Human artinya karena menampilkan ibu Anti yang menceritakan bahwa tidak hanya mendapatkan penghasilan paska kepergian suami untuk selamanya namun juga mendapatkan solusi untuk mengasuh putranya yang autis. Dengan narasi yang menyentuh emosi pembacanya, diharapkan pembaca merasakan memiliki kedekatan emosi dengan tokohnya

Strategi ketiga yang dilakukan adalah Customer-led storytelling, dengan tujuan untuk meningkatkan engagement masyarakat terhadap bisnis sosial Syarihub maka dihadirkan cerita pengalaman positif dari para pelanggan.
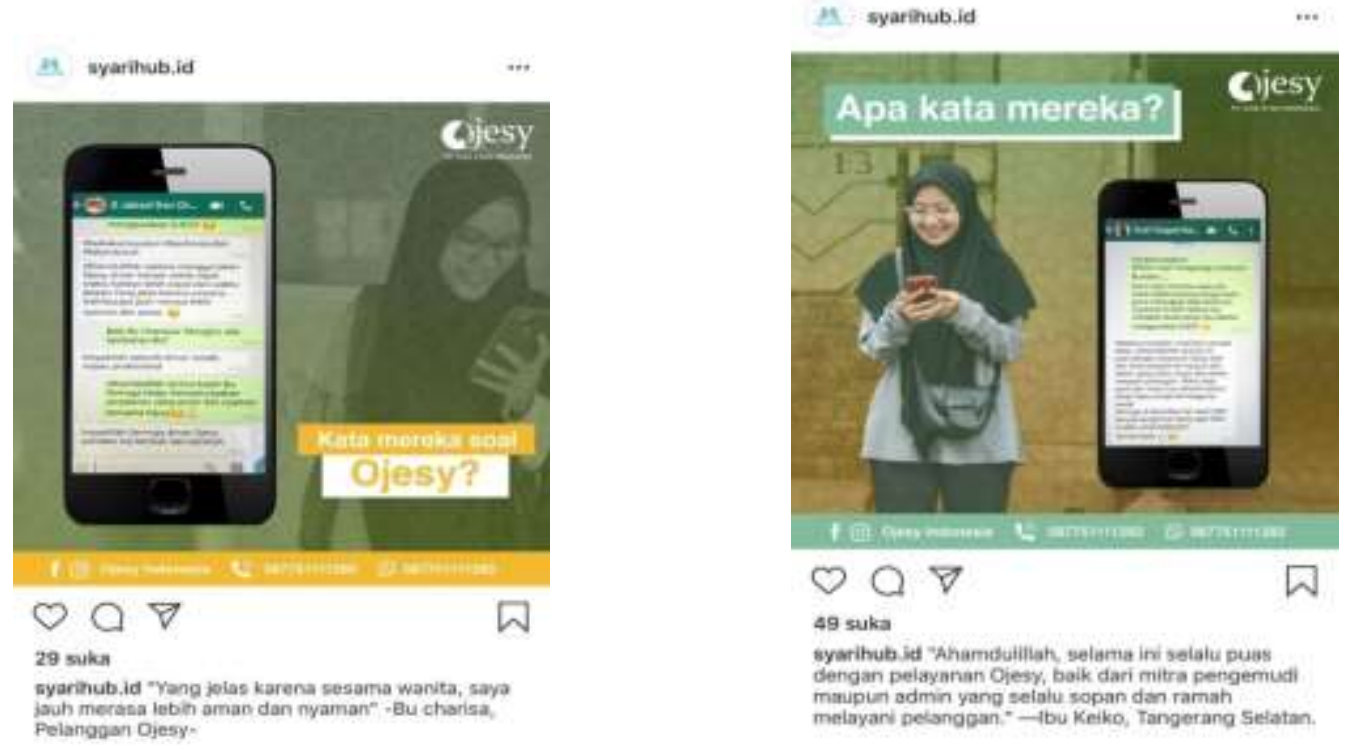

\section{Gambar 4 : Customer Led-Storytelling Syarihub pada Instagram}

Sumber : akun Instagram Syarihub.id (2018)

Strategi keempat adalah Immersial Story Telling atau Visual Story Telling yaitu : strategi pemasaran yang memanfaatkan narasi menarik, menempatkan konsumen di jantung cerita dan direalisasikan dengan media visual yang secara emosional untuk pengalaman berbelanja kostumer. Syarihub memang secara langsung belum pernah membuat sendiri namun Immersial Story Telling atau Visual Story Telling diperoleh dari liputan - liputan TV seperti pada program Hitam Putih (TransTV), Halal Living (Net TV). Sebelum liputan dilakukan maka konten liputan dan juga pemilihan narasumber telah didiskusikan antara Syarihub dan jurnalis TV.

Berikut adalah narasi - narasi storytelling yang terdapat pada salah satu liputan televisi swasta di Indonesia (NET TV) tentang Syarihub yang juga ditayangkan pada channel youtube dengan judul Halal Living - jalan - Jalan Di Surabaya Pakai Ojek Syari (sumber : https://youtu.be/alld44x9Fbc ). Apabila diamati lebih lanjut Immersial Story Telling juga mencakup data driven storytelling, phylantropic storytelling serta customer-led storytelling, 
Tri Siwi Agustina

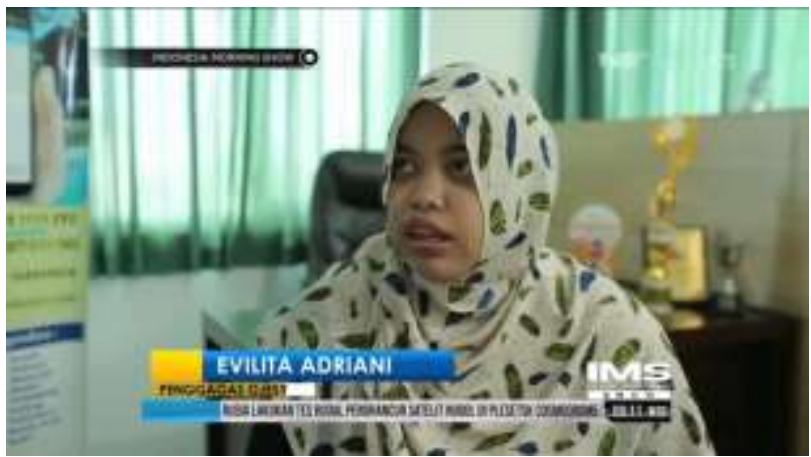

Gambar 5. Immersial Story Telling atau Visual Story Telling pada liputan televisi

Narasi (1) :

“...akhirnya saya bertemu dengan Evilita, mahasiswi salah satu Univesitas di Surabaya penggagas Ojek Syari, Pengalamannya menjadi single-fighter kurir pengantar barang keliling kota Surabaya serta masifnya tindak kejahatan dan kekerasan terhadap perempuan, serta kebutuhan terhadap transportasi perempuan menjadi alasan Evilita untuk mendirikan Ojesy sejak tiga tahun silam”.

Narasi tersebut bercerita untuk menggugah emosi pemirsa dengan menyajikan pengalaman founder Syarihub sebagai kurir pengantar barang dan fenomena permasalahan sosial yang dicoba dicarikan jalan keluarnya.

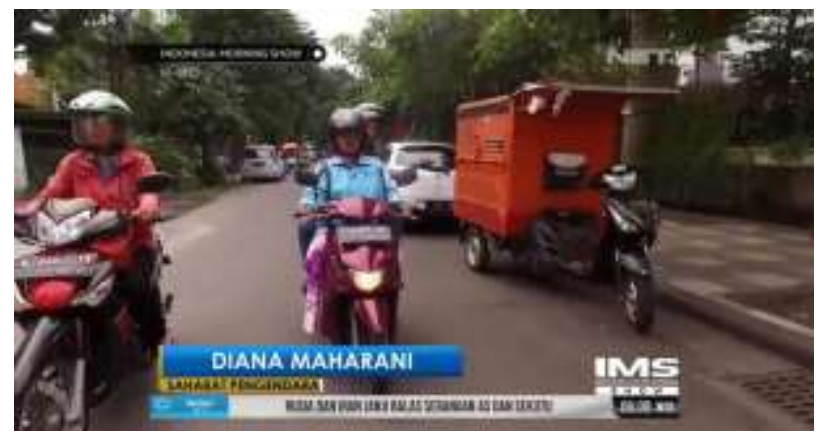

Gambar 6. Immersial Story Telling atau Visual Story Telling pada liputan televisi

Narasi (2) :

“Ibu Diana sudah menjadi sahabat pengendara lebih dari 2,5 tahun dengan memperoleh penghasilan lebih dari 2.5 juta perbulan"

Dialog Reporter dan Sahabat Pengendara :

Reporter: "Kenapa sih bu kok memilih ojek syari ? "

Sahabat Pengendara : "karena jam kerjanya fleksibel, kalo kerja kantoran tidak bisa. Disini pagi sebelum saya bekerja masih bisa mengurus anak-anak" 


\section{Tri Siwi Agustina}

Narasi yang disertai tayangan reporter yang dibonceng sahabat pengendara tersebut bercerita tentang pengalaman dan manfaat secara ekonomis dan sosial yang diperoleh setelah bergabung sebagai sahabat pengendara.

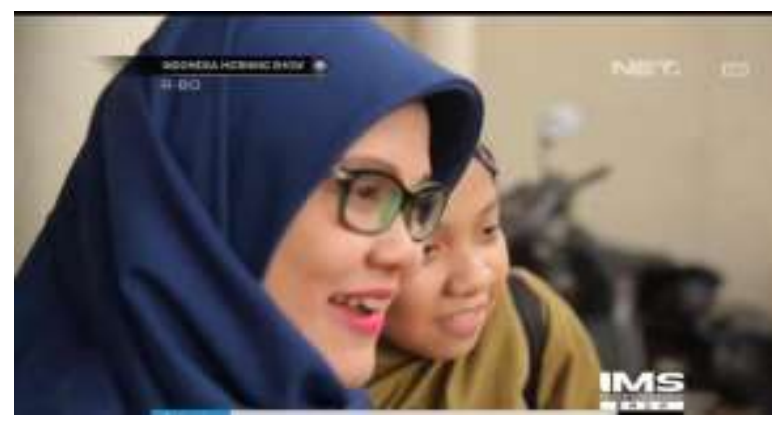

Gambar 7. Immersial Story Telling atau Visual Story Telling pada liputan televisi

Narasi (3) :

" Kebanyakan pelanggan ojek ini adalah ibu dan anak. Benar saja karena banyak orang tua yang khawatir terhadap masivnya tindak kejahatan terhadap anak di kota besar"

Testimoni pelanggan :

“ Paling tidak hilang satu kekhawatiran, selain itu mengingat anak saya perempuan dan usianya mendekati akil baligh, maka saya merasa "safe" apabila drivernya sama - sama perempuan.

Narasi yang diikuti tayangan yang menyuguhkan gambar ibu, anak yang baru pulang sekolah dan sahabat pengendara berisi testimoni pelanggan dari Syarihub semakin menguatkan data-driven storytelling sebelumnya tentang masifnya tindak kejahatan dan kekerasan terhadap perempuan dan anak - anak dan pilihan menggunakan layanan Syarihub merupakan pilihan yang tepat.

\section{Storytelling untuk menghadapi Re-branding dan pesaing - pesaing baru}

Penggagas Ojek Syari, Evilita Adriani dan Reza Zamir, pada tahun 2019 memberi nama usahanya "Syarihub" di bawah bendera PT. Ojek Syari Indonesia. Nama Ojesy tak lagi dipakai setelah kasus konflik dengan seorang pendiri lainnya yang kini telah keluar. Pasca konflik internal, dirasa perlu untuk menyampaikan pada masyarakat tentang perubahan nama Ojesy menjadi Syarihub agar pelanggan tidak bingung dengan nama baru serta logo baru.

Dalam kurun waktu 4 tahun beroperasi, Syarihub menghadapi tantangan persaingan baik dari ojek online konvensional (Gojek dan Grab), terdapat pesaing - pesaing serupa dengan menyasar khusus pada segmen pasar yang unik (market niche) yakni perempuan dan berbasis syariah, misalnya Fathimah Safety Ojek (FSO) beroperasi di wilayah Yogyakarta, Ojesa (Ojek Akhwat Indonesia) beroperasi di wilayah Bandar Lampung, Metro dan Palembang, Shejek beroperasi di wilayah Jawa Barat, Malang, Makasar, Yogyakarta, Pekanbaru dan Samarinda (Sumber : https://beritagar.id/artikel/laporan-khas/lika-liku-ojek-syariah-di-indonesia). 


\section{Tri Siwi Agustina}

Perubahan nama dari Ojesy menjadi Syarihub sekaligus dijadikan sebagai momen rebranding dari bisnis syarihub yang semula hanya mengantar orang dan barang bertransformasi sebagai aplikasi kebutuhan syariah, dengan tambahan berupa layanan catering subuh, pengasuh anak muslimah, serta mentor mengaji, seperti yang terdapat pada gambar 6 .

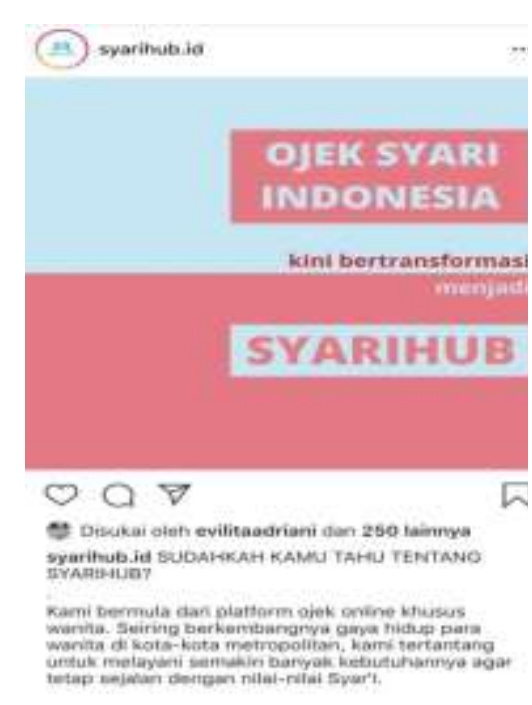

Gambar 8. Storytelling tentang Re-branding Syarihub.

Sumber : Instagram Syarihub (2019)
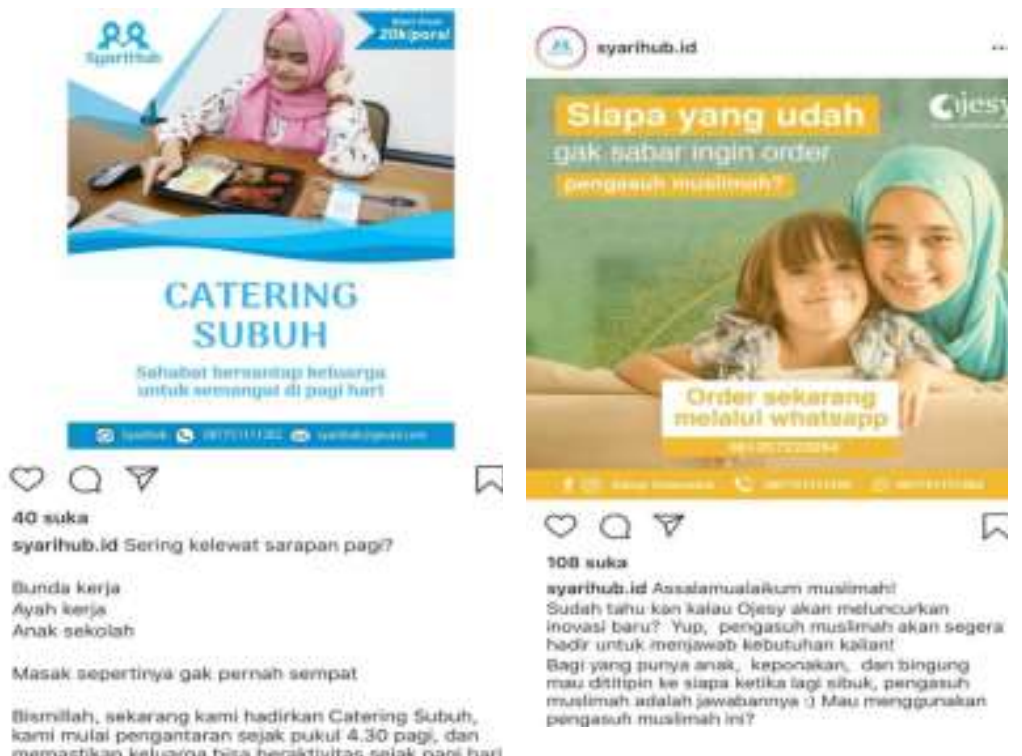

Re-branding yang dilakukan Syarihub tidak hanya ditandai dengan diversifikasi usaha saja namun juga memperluas kesempatan kerja bagi wanita muslimah akan akses pekerjaan. Ide melakukan diversifikasi usaha berupa Catering Subuh, Pengasuh Muslimah dan juga guru mengaji didasarkan pada kebutuhan pasar dari ceruk yang sama (yakni wanita sebagai ibu rumah tangga). Syarihub mempertemukan demand dari ibu rumah tangga yang bekerja yang memiliki keterbatasan waktu untuk menyiapkan sarapan pagi dengan memberikan akses pekerjaan kaum wanita muslimah yang memiliki keahlian memasak. Hal ini berlaku pula bagi Pengasuh Muslimah dan Guru mengaji.

Seiring dengan perjalanan bisnis Syarihub hingga tahap re-branding saat ini nampak bahwa bisnis sosial ini semakin mendapatkan penerimaan masyarakat, hal tersebut dapat diketahui dari makin banyaknya pihak - pihak yang terlibat dan mendukung kelangsungan bisnis Syarihub, misalnya :

1) Pertumbuhan jumlah wanita yang melamar sebagai mitra pengendara $60 \%$ dari kurun waktu tahun 2018 ke tahun 2019 , penambahan jumlah mitra pengendara juga dapat diartikan terjadi penambahan armada dengan wilayah yang tersebar di Surabaya, Sidoarjo, Malang dan Makasar. Dengan penambahan jumlah armada dan jumlah pelanggan membawa dampak pada penurunan tarif admin dan tariff per kilometer

2) Pertumbuhan jumlah pelanggan $90 \%$ pertahun.

3) Pembinaan dari Pemkot Surabaya : Syarihub terpilih sebagai salah satu startup yang dibina oleh Pemerintah Kota Surabaya karena dinilai telah membantu mengatasi 
permasalahan sosial di kota Surabaya (terutama pemberdayaan perempuan dengan menyediakan akses kesempatan kerja). Bentuk binaan yang diberikan adalah mengirimkan founder untuk mengikuti pelatihan tentang start-up berbasis teknologi di Silicon Valley Amerika Serikat. Selain itu Pemkot Surabaya juga memfasilitasi ruangan di KORIDOR Surabaya (Co-Working Space milik Pemkot Surabaya) sebagai kantor dari Syarihub.

4) Pada bulan Oktober 2018, Syarihub terpilih sebagai salah satu startup yang dibina oleh IDX Inkubator berbasis teknologi. Program inkubasi berlangsung selama 6 bulan dengan pendampingan berupa validasi ide pengembangan produk, penelitian pasar hingga menyiapkan startup siap untuk IPO (Initial Public Offering).

5) Syarihub juga lolos untuk menjadi tenant bimbingan incubator bisnis Universitas Airlangga

6) Menjajagi kerjasama dengan Griya Al-Quran Surabaya dalam bentuk penyaluran tenaga guru mengaji

Uraian hal tersebut diatas membuktikan pernyataan peneliti sebelumnya Roundy (2014) dan Lindawati, (2018).yang menyatakan bahwa seorang sociopreneur sudah seharusnya membangun narasi untuk berkomunikasi dengan stakeholder. Narasi atau cerita ini mempunyai peran besar dalam membangun relasi, baik dengan konsumen, relawan, maupun investor, artinya selain menarik minat konsumen cerita bagi sosiopreneur juga penting untuk membangun multistakeholder partnership.

Hasil lain dari penelitian ini adalah dari 6 (enam) strategi storytelling : Data driven storytelling, Philanthropy storytelling, Customer-led storytelling, Immersial story telling, Mini Ads dan Dark Triad. Strategi Mini Ads dan Dark Triad belum dilakukan oleh Syarihub karena alasan efisiensi biaya. Hal tersebut sangat beralasan mengingat usia startup Syarihub yang baru 4 tahun beroperasi, dimana manajemen Syarihub memiliki skala prioritas dalam strategi promosi pemasarannya dan juga dalam penggunaan arus kasnya.

\section{Kesimpulan}

Storytelling merupakan media promosi yang tepat untuk bisnis sosial, karena bisnis sosial memprioritaskan value sosial daripada perolehan profit. Value sosial yang dimiliki oleh sosiopreneur dapat diceritakan mulai dari latar belakang berkiprah sebagai sosiopreneur, misi sosial yang diemban, program - program dan tanggapan masyarakat. Hal tersebut dilakukan tidak hanya untuk menarik masyarakat untuk melakukan action namun juga sebagai upaya untuk membangun multistakeholder partnership.

Storytelling telah dilakukan manajemen Syarihub sebagai strategi pemasaran di era digital serta menjawab tantangan - tantangan dalam mengepakkan sayap bisnisnya dalam bentuk Data driven storytelling, Philanthropy storytelling, Customer-led storytelling dan Immersial story telling. Media Storytelling yang digunakan adalah website dan media sosial seperti facebook, twitter dan instagram. Pembuatan storytelling dilakukan langsung (artinya dikelola oleh admin Syarihub) maupun tidak langsung (kerjasama dengan media misalnya liputan program televisi). 
INOBIS: Jurnal Inovasi Bisnis dan Manajemen Indonesia Volume 03, Nomor 04, September 2020

Tri Siwi Agustina

\section{Daftar Pustaka}

Lindawati, L, (2018) “Kekuatan Cerita Pada Bisnis Sosial” Jurnal Studi Pemuda, Vol 7 (2), 100

https://www.researchgate.net/publication/331208497_Kekuatan_Cerita_dalam_Bisni s_Sosial_Sociopreneur_is_A_Storyteller, DOI: 10.22146/studipemudaugm.39643

Mair, J., \& Marti, I., (2004), Social Entrepreneurship research : source of explanation, prediction and delight. Retrieved August 3, 2019 from http://www.iese.edu/research/pdfs/DI-0546-E.pdf

Roundy, P. (2014), "The stories of social entrepreneurs: Narrative discourse and social venture resource acquisition", Journal of Research in Marketing and Entrepreneurship, Vol. 16 No. 2, pp. 200-218. https://doi.org/10.1108/JRME-06-2014-0009

Ryder.P., \& Vogeley, J., (2017), Telling the impact investment story through digital media : an Indonesia case study. Communication Research and Practice, 1-23. DOI : 10.1080/22041451.2017.1387956,

https://researchers.mq.edu.au/en/publications/telling-the-impact-investment-storythrough-digital-media-an-indo,

Seelos, C., \& Mair.,J., (2005). Social Entrepreneurship has also been characterized as creating new business models to serve the poor. Business Horizons, 48, 241-246, (PDF) Social Entrepreneurship: Creating New Business Models to Serve the Poor (researchgate.net) DOI: $10.1016 /$ j.bushor.2004.11.006

Wan-Tzu, L \& Shyhnan, L, (2016). "How social enterprise attract public awareness using storytelling," Proceedings of International Academic Conferences 3505862, International Institute of Social and Economic Sciences.”. Jurnal Economia, 2(1), 111, DOI: $10.20472 / \mathrm{IAC} .2016 .022 .034$

https://beritagar.id/artikel/laporan-khas/lika-liku-ojek-syariah-di-indonesia

https://www.brilio.net/news/layanan-ojek-khusus-wanita-ini-syaratkan-pengojeknya-harusberkerudung-1510050.html\#

https://www.cnnindonesia.com/teknologi/20150813085048-185-71833/gojek-dan-grabbikeakhiri-perang-tarif

https://www.facebook.com/OJESYIndonesia/posts/cerita-sahabatbu-anti-bekerja-dan-

bermanfaat-bersama-ojesykisah-ini-bukanlah-seb/1562578407371215/

https://gojekinfoupdate.blogspot.com/2019/03/naik-turun-tarif-gojek-hingga-2019.html

https://www.merdeka.com/foto/jakarta/644224/20151230213924-intip-pelatihan-driver-ojeksyari-ojesy-002-isn.html

https://selular.id/2015/10/ojek-syari-larang-driver-mangkal-di-jalan/ https://visme.co/blog/ask-me-anything-with-shlomi-ron/ 